\title{
AN OBJECTIVIST'S GUIDE TO SUBJECTIVE REASONS
}

\author{
Daniel Wodak
}

\begin{abstract}
The distinction between objective and subjective reasons plays an important role in both folk normative thought and many research programs in metaethics. But the relation between objective and subjective reasons (or, more aptly, objective and subjective favoring) is unclear. This paper explores problems related to the unity of objective and subjective reasons for actions and attitudes and then offers a novel objectivist account of subjective reasons.
\end{abstract}

The distinction between objective and subjective reasons plays an important role in both folk normative thought and many research programs in metaethics. But what is the relation between objective and subjective reasons? Are they species of a genus? If so, what is their essence, and what is the differentia? Does one reduce to the other? If so, how does the reduction go? Or are they utterly dissimilar entities, like jadeite and nephrite? There's much at stake between these options. As Schroeder $(2018,290)$ points out, the "core case" that motivates the Reasons First program is that what we ought to do is determined by what we have reason to do. But since we need to distinguish "a subjective 'ought' of rationality" from "an objective 'ought' of advisability," with subjective reasons explaining the former and objective reasons explaining the latter, there must be a "close relationship between objective and subjective reasons." Reasons First would be an unattractive research program if it posited that normativity is explained in terms of utterly dissimilar entities.

The most popular option in the current literature is 'objectivism.' The objectivist claims that subjective reasons reduce to objective reasons. Despite being the most common view in the literature (endorsed, in different forms, in influential work by Mark Schroeder, Derek Parfit, Jonathan Way, Eric Vogelstein, Kurt Sylvan, and Daniel Whiting), prominent forms of objectivism face serious-perhaps fatal-objections.

I have two main aims in this paper. The first is to offer a new objection to prominent forms of objectivism. Unlike many objections in the current literature, it does not focus on extensional problems for objectivists. It turns on whether objectivists can deliver a unified account of favoring. 
The second is to defend, schematically, a very different objectivist account of subjective reasons. The main point of departure will be to cease seeking to explain all subjective reasons to $\varphi$ in terms of objective reasons to $\varphi$, and instead explain everything in terms of objective reasons for belief.

\section{The Unity of Reasons}

The familiar dialectic is roughly as follows. Many metaethicists think we can analyze facts about what one ought to do in terms of facts about reasons, but then we notice a distinction between objective and subjective 'ought's. This distinction prompts a bifurcation between objective and subjective reasons. If we are explaining facts about what one ought to do in terms of facts about reasons, objective and subjective reasons need to be unified. ${ }^{1}$

It should not be surprising that this issue arises here. "Issues of unity arise," Jonathan Schaffer $(2016,143)$ wrote, "with virtually all interesting philosophical concepts." There's a debate about whether there is one unified grounding relation, rather than a motley crew of dissimilar relations (composition, set membership, and the like). There's a debate about whether there's one unified causation relation, rather than a smaller coterie of dissimilar relations (probabilification, counterfactual dependence, and energy transfer). If we posit a distinction between objective and subjective reasons, we should ask: Are they unified? Interestingly, people do ask this question a great deal apropos, for example, the distinction between epistemic and practical reasons. But surprisingly little has been said about the unity of objective and subjective reasons.

I will make four points about how objectivists address this issue of unity. The first is simple. Many objectivist accounts of subjective reasons just don't address the problem of the issue of unity at all. Sometimes this is even made explicit. Daniel Whiting $(2014,20)$ provided an objectivist account of subjective reasons and then immediately confessed that it leaves unanswered the question: "In what sense are subjective reasons reasons?" To my mind, that question is crucial. Without an answer to it, it's not clear how much progress an objectivist account of subjective reasons can make.

The second point is more substantive. When the issue of unity is addressed in relation to objective and subjective reasons, it is often misunderstood. Here's what Vogelstein $(2012,250)$ has to say about it:

that subjective reasons are propositions [. . .] has an important advantage of simplicity over rival theories: it allows for a unified account of normative reasons generally.

\footnotetext{
${ }^{1}$ I think these appeals to 'unity' in metaethics are somewhat under-theorized. See Wodak Unpublished manuscript $a$ for further discussion of how that bears on Reasons First and its rivals. (Though what I say here does not depend on the positive view about unity in that paper.)
} 
It is a commonplace that objective reasons are facts, and according to a prominent and plausible view, facts just are true propositions.

I don't think Vogelstein is alone in this focus on the 'unity of reasons.' But consider an analogous position about causation. Does the view that all causes and effects are events allow for a unified account of causation? Not at all. Causes and effects are the relata, not the relation itself. Different relations can obtain between the same relata. The relation of being temporally posterior to obtains between events, but it is still utterly different from being a cause of. We don't have, and shouldn't want, a unified account of being temporally posterior to and being a cause of, even though they plausibly have the same relata, because they're dissimilar relations. And so if the term 'causation' itself seems to pick out relations that are dissimilar in the way that being temporally posterior to and being a cause of are dissimilar, it does not help at all to point out that the relata are still events.

Likewise, I believe, what really interests metaethical accounts of reasons is not the relata, but the relation (being a consideration in favor of, or just favoring). Reasons might all be propositions, without that settling whether the favoring relation is unified. If that isn't obvious, just consider all the other relations that obtain between propositions, and note how strange it would be to say that we have a unified account of favoring and any other relation just because with both relations propositions are among the relata. For instance, on many views grounding is a relation that obtains between facts, and facts (as Vogelstein reminds us) may just be true propositions. But that doesn't unify the grounding relation and the favoring relation. ${ }^{2}$

This is not to say that it's irrelevant whether all reasons turn out to be propositions. It's to say that unifying a relatum does not in itself unify the relations that are of philosophical interest. The point is that just as unifying causes does not unify causation, unifying reasons does not unify favoring.

The third point comes into focus once we make this distinction between the favoring relation and its relata. It's a near consensus that reasons can favor actions or attitudes. ${ }^{3}$ But the literature on objective and subjective reasons often focuses solely on reasons for actions. Aside from some discussion of objective and subjective reasons for belief, ${ }^{4}$ very little is said about the objective and subjective reasons for a diverse array of attitudes.

\footnotetext{
${ }^{2}$ If you doubt this last point, notice that a substantive view here is that we can analyze the favoring relation in terms of the grounding relation: to be a reason is to be a 'right-maker,' or a fact that grounds rightness. (For views in this ballpark, see Schroeter and Schroeter 2009, Markovits 2010, Alvarez 2010, Broome 2013, and Hyman 2015. For a recent discussion of some of the problems that they face, see Whiting 2017.) That favoring and grounding both take propositions as a relatum does not guarantee that this substantive view about reasons is true. See Wodak Unpublished manuscript $b$ for discussion of that view.

${ }^{3}$ For a dissenting view, see Maguire 2018 and cf. Faraci Forthcoming.

${ }^{4}$ For general discussion, see Sylvan and Sosa 2018 and references therein.
} 
To get a sense of the lacuna here, consider Fitz and Gödel. Fitz admires Gödel for his mathematical achievements, but discovers that Gödel stole his famous theorems from some poor schmuck named Schmidt. Intuitively, Fitz had a subjective reason to admire Gödel, but, plausibly, there was no objective reason for him to do so. Fitz's case is just like paradigm cases of subjective reasons (he admired Gödel on the basis of false full beliefs), but the reasons are for admiration rather than actions. I contend that it will be easy to find cases like Fritz's for any attitude that has correctness conditions. Here I am relying on Judith Jarvis Thomson's (2008, 130-132) distinction between mental states like belief (it is correct to believe $p$ iff $p$; truths deserve to be believed), and those like dizziness (there is no correct or incorrect dizziness; nothing deserves your being dizzy).

Why does recognizing objective and subjective reasons for attitudes make it harder for objectivists to unify objective and subjective reasons? For one, insofar as we care about the unity of the relata, we can't just focus on reasons. We also need to focus on what they are reasons for: actions or attitudes. In other words, even if reasons are always propositions, more needs to be said to unify the relata of the favoring relation. ${ }^{5}$ (I don't want to put much weight on this point given what I said above about the unity of the relation [favoring] being what's most significant in this context.)

The other, more substantive point is that it's not obvious that current objectivist accounts of the distinction between objective and subjective reasons for action are well placed to explain distinctions between objective and subjective reasons for attitudes. In that sense, they fail to provide a fully general account of the distinction between objective and subjective reasons. I'll discuss three objectivist accounts to illustrate why this is so.

Consider popular objectivist counterfactual analyses, like the following:

C: $p$ is a subjective reason for $A$ to $\varphi$ iff and because (a) $A$ believes $p$, and (b) if $p$ were true, $p$ would be an objective reason for $A$ to $\varphi .^{6}$

To illustrate $C$, say that you see a poisonous snake and believe it will strike you iff you stay near, but in fact it will strike you iff you run away. The objective reasons militate strongly in favor of staying put, but you still have a subjective reason to run away. Why? Because you believe the proposition $<$ the snake will strike you iff you stay near>, and if that proposition were true it would be an objective reason for you to run away. So far, so good. But apply $\mathrm{C}$ to the reasons for belief: $p$ is a subjective reason for $A$ to believe $q$ iff and because (a) $A$ believes $p$ and (b) if $p$ were true, $p$ would be an objective reason for $A$ to believe $q$. I think this introduces boot-strapping concerns quite trivially. Recall Thomson: truths deserve to be believed; the

\footnotetext{
${ }^{5}$ I don't mean to suggest that the reasons-relation is only a two-place relation here. The point works just as well if one takes the favoring relation to be a four-place relation: a relation between a proposition (or fact), an agent, a circumstance, and an act or attitude.

${ }^{6} \mathrm{C}$ is a slight simplification of the counterfactual analyses that are endorsed by Schroeder (2007, 14; 2009, 233), Parfit (2011, 111), Way (2009, 3), and Vogelstein (2012, 250).
} 
fact that $p$ is the paradigmatic objective reason to believe $p .^{7}$ So for any $p$, if I believe it and it were true, it would be an objective reason to believe $p$. So I have subjective reason to believe $p$ whenever I believe $p$. To many, ${ }^{8}$ that implication is quite implausible.

Next, consider Sepielli. He takes the central concern with subjective normativity to be explaining some kind of action-guidance (2012; 2018). I am not sure whether there is any equivalent puzzle in explaining admirationguidance. There might be, but it seems like a substantive question. So it is unclear how well motivated his objectivist account will be when we turn our attention to reasons for attitudes. His account would be, roughly, that Fritz has subjective reasons to admire Gödel insofar as Fritz is trying to admire the person who he has most objective reason to admire. I'm not sure how compelling that analysis is, in part because, as Sepielli says (2012, 51), our "most primordial use" of the concept TRYING "is in action." I know how to try to score a touchdown. I don't know how to try to admire Gödel. This might just point to a difference in the phenomenology, but the phenomenology of trying is part of what drives Sepielli's project. I don't mean to suggest that these are decisive objections to Sepielli's view. They're not. They're important questions that are left unasked and unanswered due to the sole focus on the distinction between objective and subjective reasons for actions.

Finally, consider Whiting's view: $p$ is a subjective reason for $A$ to $\varphi$ iff and because it is a priori that, if the facts of the situation are as they appear to $A, p$ is an objective reason for $A$ to $\varphi$. This view also faces challenges with objective and subjective reasons for attitudes. Say I admire Gödel for his mathematical discoveries. And this time, he didn't steal them. He was just wrong, unbeknownst to everyone. The problem is: if Gödel is wrong, it's a priori that he's wrong, because mathematics-or at least, the area of mathematics involved in Gödel's theorem-is a priori. So a serious question arises here: Can we have subjective reason to admire Gödel in such cases? There are solutions available to Whiting. ${ }^{9}$ Perhaps we consider what would be the case if, per impossibile, Gödel was right. But making this shift to

\footnotetext{
${ }^{7}$ I don't have space to defend the commitment that the fact that $p$ is an objective reason to believe $p$, but it's defensible. (Sylvan and Sosa [2018] write: "When it is a fact that P, this fact is the best objective reason there could be to believe P." See also Schroeder 2015.) So it should concern objectivists if this commitment wreaks havoc for their views.

${ }^{8}$ But not to all: it may be acceptable on some forms of epistemic conservatism. (Thanks to Jack Woods for pointing this out.) Still, objectivists shouldn't be committed to conservatism. ${ }^{9}$ Whiting's own view on this matter seems to be that "what is a priori is a relative matter; specifically, it is relative to a subject's cognitive capacities" $(2014,14)$. As comes out in Errol Lord's discussion of Whiting's piece, this doesn't solve the original problem (see Lord's related case of Vlad the mathematician), and raises several new problems: "it seems to follow that in order to have subjective reasons at all, one needs to have the concept <objective reason >"; and it follows that one cannot have subjective reasons if one's cognitive capacities are constrained with respect to reasoning about reasons. See the discussion on PeaSoup. Errol Lord, "JESP Discussions at PEA Soup: Daniel Whiting's 'Keep Things in Perspective: Reasons, Rationality and the A Priori' with a Critical Précis from Errol Lord." PeaSoup. June 6,
} 
impossible worlds undermines the initial motivation for Whiting's view, which was driven by the problems that $\mathrm{C}$ faces with counterfactuals that have necessarily false antecedents $(2014,9)$.

The simple upshot here is that it looks quite hard to provide a fully general account of the distinction between objective and subjective reasons: that is, an account that works just as well for reasons for actions and for reasons for attitudes. And if objectivists can't deliver that, then at best they can deliver different accounts: one account for objective and subjective reasons for action, and at least one more for objective and subjective reasons for attitudes (or, worse yet, one for belief, another for desire, and more still for other attitudes like admiration). If that is where objectivists end up, they will have failed to unify objective and subjective reasons, even if they had succeeded in unifying objective and subjective reasons for action. To be clear, there's more to be said about these objectivist theories, and indeed I've developed related objections to them at greater length elsewhere. ${ }^{10}$ The overarching point, put simply, is that the overwhelming focus in the literature on objective and subjective reasons for actions is unfortunate.

The fourth and final point is perhaps the most significant. I think some of the ways in which objectivists are trying to unify the relation of favoring try to give us a form of unity that's just too cheap. This point won't move everyone. It partly hinges on whether you think objective and subjective reasons are distinctive ways of favoring, such that both are normative.

Let me back up a little to bring this point into focus. Compare two routes that you could go down if you wanted to see whether or how jade is unified. One route is committed to the thought that we're trying to unify a worldly entity, a mineral. And this route naturally leads to the conclusion that jade is disunified, because jade consists of jadeite or nephrite, and jadeite and nephrite-as worldly entities-are utterly dissimilar. (Molecularly, jadeite is $\mathrm{NaAlSi}_{2} \mathrm{O}_{6}$; nephrite is $\mathrm{Ca}_{2}\left(\mathrm{Mg}, \mathrm{Fe}_{5}\right)_{5} \mathrm{Si}_{8} \mathrm{O}_{22}(\mathrm{OH})_{2}$.) But you could take a different route and reach a different result. Maybe you just care about unifying something like concepts (where concepts are understood in some psychological sense, rather than as Fregean abstracta). And then you could analyze the concept NEPHRITE as MINERAL-THAT-IS-BELIEVED-TOBE-JADEITE. There is a sense in which this analyses NEPHRITE in terms of JADEITE. And in that sense, it might provide a kind of unity. I tend to think this kind of unity is cheap and philosophically uninteresting.

But surprisingly, many objectivist accounts of subjective reasons look suspiciously like this view about jade. They use the concept OBJECTIVE REASON in analyzing SUBJECTIVE REASON, largely by embedding the former under something that has nothing to do with reasons (a la MINERALTHAT-IS-BELIEVED-TO-BE- . . . ). Call this the strategy of conceptual embedding.

2014. http://peasoup.us/2014/06/jesp-discussions-at-pea-soup-daniel-whitings-keep-thingsin-perspective-reasons-rationality-and-the/.

10 On C, see Wodak 2017; Vogelstein 2012; Whiting 2014; and Sylvan 2015. 
For instance, on some views, one's subjective reasons are the propositions that one takes to be objective reasons, or believes to be objective reasons. ${ }^{11}$ To my mind, this no more unifies reasons than the above analysis unifies jade. It's important, again, that our interest is in the relations, not the relata. The point is that on this view, one relation is that of favoring (objective reasons are facts that count in favor of actions or attitudes), while the other is the relation of being believed to favor (subjective reasons are propositions one believes to count in favor of actions or attitudes). The two relations are utterly dissimilar. Subjective reasons don't favor at all.

Now consider the account in Sepielli $(2012,51 ; 2018)$. His view is framed in terms of OUGHT, not REASON, but it is clearly intended to generalize to other distinctions between subjective and objective normativity. To Sepielli, we can define what I subjectively ought to do as my "best try" at doing what I have objective reason to do. To my mind, TRY functions in this analysis like BELIEF did in the one above. It allows us to embed the desired explanandum in our account of the target explanans. But it does not unify the two, as on the full view, the objective reasons relation turns out to be about facts counting in favor of actions and attitudes, and the subjective reasons relation turns out to be about certain attempts. These attempts do not, in themselves, count in favor of anything. An analogy might help here. ${ }^{12}$ On Sepielli's view, objective reasons are like touchdowns and subjective reasons are like failed offensive plays. Touchdowns actually put points on the board and count towards the score, just as objective reasons count in favor of actions or attitudes. But failed offensive plays don't do this; they're attempts to be things that put points on the board, but they don't actually count toward the score in any sense. Analogously, subjective normativity turns out not to be normative.

Again, this problem might not move you. I think it should move you insofar as you care about unifying worldly normative relations, and think that objective and subjective reasons are both worldly normative relations. These commitments are deeply held by many, but they're tough to defend. So one way to go in response here might be to give them up, and that's not entirely unprecedented. Another way metaethicists sometimes talk about 'objective and subjective reasons' is in terms of 'reasons and apparent reasons'; this way of framing the phenomenon, as Kiesewetter (2012) pointed out, leads more naturally to the conclusion that we're dealing with normativity and apparent normativity. That is a striking conclusion to reach. It suggests that all 'oughts' that are analyzed in terms of subjective

\footnotetext{
${ }^{11}$ See for example, Dorsey 2012. Scanlon $(1998,25)$ can be read to suggest such a view too. Early views about objective and subjective normativity follow this pattern: see Feldman 1988.

${ }^{12}$ In case the football example doesn't help, here's another. On my view, 'objective and subjective reasons' are more like homicide and suicide, whereas on Sepielli's view 'reasons and apparent reasons' are more like homicide and attempted homicide. Homicide and suicide are different ways of killing. Homicide and attempted homicide are not; but there's still a sense in which both can be understood in terms of HOMICIDE.
} 
reasons-like "the subjective 'ought' of rationality" - aren't really normative. But if one takes this route, then we aren't really dealing with two worldly normative relations, so the cheap kind of unity that one can achieve via the strategy of conceptual embedding may be satisfying.

\section{A Guide to Unexplored Terrain}

My goal above isn't to persuade you that each and every existing objectivist account is a dead end. And my goal below isn't to convince you that I have a complete and unimpeachable alternative. Rather, I'm trying to motive exploring a different objectivist approach to subjective reasons.

The starting point turns on the following observation from Wodak 2017. There's a way in which all current objectivist accounts are very similar, and similarly narrow. They all seek to explain the subjective reasons for $A$ to $\varphi$ in terms of the objective reasons for $A$ to $\varphi$ (where ' $\varphi$ ' stands for actions or attitudes). This leaves unexplored a vast area of conceptual space: namely, explanations of the subjective reasons for $A$ to $\varphi$ in terms of the objective reasons, but not necessarily objective reasons for $A$ to $\varphi$. The view I want to develop is schematic, because I'm attempting to chart one region of that conceptual space and survey what resources it offers. This is intended to be an exploratory mission that can serve as a guide for fellow travelers; I don't aim to plant a flag on some narrow region of the terrain.

There are two main steps in the approach I'll be exploring. The first is to reduce all the distinctions between objective and subjective reasons for actions and non-doxastic attitudes to the distinction between objective and subjective reasons for belief. The second is to show how available positions in epistemology about the distinction between objective and subjective reasons for belief promise to solve the problems I posed above. I'll consider the first goal in this section and defer the second until section 3.

How might we reduce the distinctions between objective and subjective reasons for actions and admiration, say, to the distinction between objective and subjective reasons for belief? Let's take admiration first.

Recall Thomson's distinction between attitudes with and without correctness conditions. Admiration is a paradigmatic case of the former. It is correct for Fitz to admire Gödel iff Gödel is admirable. Notice that these correctness conditions are propositions (<Gödel is admirable>), which one could believe. Thomson (2008, $130 \mathrm{ff}$.) argues that for any attitude with correctness condition, reasons for that attitude reduce to reasons to believe that the correctness condition obtains-that is, reasons to admire Gödel are reasons to believe the proposition $<$ Gödel is admirable $>$. $^{13}$

\footnotetext{
13 This commitment is not just to the necessary co-extensionality of reasons to admire Gödel and reasons to believe that Gödel is admirable, but to the explanatory priority of the latter. The same goes for the other reductive theses that I mention as part of the picture below. An anonymous referee presses that the claim about explanatory priority needs to be defended independently of the claim about necessary co-extensionality. That's true. My hope is to show
} 
This is a significant commitment, but consider what resources become available for objectivists about subjective reasons if they take it on board. We can make the familiar distinction between objective and subjective reasons to believe <Gödel is admirable>. If Gödel is admirable, that is an objective reason to believe $<$ Gödel is admirable $>$, and hence an objective reason to admire Gödel. If the evidence supports believing <Gödel is admirable>, that is a subjective reason to believe <Gödel is admirable>, and hence a subjective reason to admire Gödel. The distinction between objective and subjective reasons for admiration reduces to the distinction between objective and subjective reasons for belief. And likewise for any other attitude with a correctness condition. So instead of having objective and subjective reasons for actions and a diverse array of attitudes, we now just have objective and subjective reasons for actions and beliefs.

Can we go further? Can a similar trick be pulled for objective and subjective reasons for action? There are several different options here.

One option is to take reasons for $A$ to $\varphi$ (where ' $\varphi$ ' stands for an action; it should also be read as such below) to be explained in terms of reasons for $A$ to intend to $\varphi$. Next, we take intentions to have a correctness condition, $x$. If the objectivist takes this route, then reasons for $A$ to intend to $\varphi$ to reduce to reasons for $A$ to believe $\langle x\rangle$, so the distinction between objective and subjective reasons for $A$ to $\varphi$ will reduce to the distinction between objective and subjective reasons for $A$ to believe $<x>$. This is not my preferred option. It may be that intentions have a correctness condition (perhaps it's correct to intend $\varphi$ iff $\varphi$ ing is 'choice-worthy'), but challenges arise once one takes reasons to intend to be prior to reasons to act.

A better option is to take reasons for $A$ to $\varphi$ to decompose into reasons for belief and desire. A flatfooted way of doing so is to take reasons for $A$ to $\varphi$ to decompose into reasons for $A$ to desire to $\psi$ and reasons for $A$ to believe that $\varphi$ ing is a means to $\psi$ ing. If one takes this route, the distinction between objective and subjective reasons for $A$ to $\varphi$ reduces to the distinction between for objective and subjective reasons for $A$ to believe $<\varphi$ ing is a means to $\psi$ ing $>.{ }^{14}$ There are less flatfooted ways of going here that similarly explain the distinction between objective and subjective reasons for action in terms of objective and subjective reasons for belief.

Now we've solved one of the issues that arose above. A plethora of distinctions between objective and subjective reasons (for actions and belief and desire and approval and . . .) reduces to one distinction. So the

that the full picture has sufficient theoretical virtues to make these commitments about both necessary co-extensionality and explanatory priority plausible. We don't explain the unity of favoring via the relevant biconditionals alone.

${ }^{14} \mathrm{I}$ 'm holding fixed that the relevant reasons for desire to $\psi$ here are objective (i.e., facts about whether $\psi$ ing is desirable). If we consider subjective reasons to desire to $\psi$ (subjective reasons to believe that $\psi$ ing is desirable), we get a different class of reasons that are sensitive to normative uncertainty, rather than descriptive uncertainty. Following Hedden (2016), we can call these 'super-subjective' reasons for action. 
objectivist just needs to provide an account of the distinction between objective and subjective doxastic reasons, and in doing so show how that account unifies the objective and subjective favoring relations.

\section{The Unity of Favoring}

Now we come to the crucial move in the objectivist account: how to reduce subjective reasons for belief to objective reasons for belief.

Here my inclination is that metaethicists should pass the buck to epistemologists, in the spirit of having an ecumenical form of objectivism about subjective reasons. Epistemologists of many stripes are committed to a bifurcation of objective and subjective epistemic notions (e.g., objective and subjective epistemic oughts, norms, or requirements), where the latter are to be explained in terms of the former; this commitment is not always expressed in the parlance of reasons, but I don't think that matters much. ${ }^{15}$ What matters is the broad consensus on two points. First, many epistemologists accept that there are some objective epistemic norms (like the following from Boghossian: "The truth is what you ought to believe, whether or not you know how to go about it" [2003, 38-39]), ${ }^{16}$ as well as other subjective epistemic norms that are relative to what's in an agent's ken. This bifurcation, many have noted, is directly analogous to the bifurcation of objective and subjective moral reasons (or oughts, requirements, norms, or what have you). ${ }^{17}$ Second, many epistemologists accept that the subjective epistemic norms are derived from the objective epistemic norms. ${ }^{18}$ This view is so entrenched that Stich reports that when he denied that truth should be the aim of our epistemic practices, many just assumed that he "must be joking" $(1990,101)$. Given the ambitions of this objectivist guide to subjective reasons, I think it's important dialectically to note that there is a vast array of epistemological views that seem to fit the bill for this detail of the picture being sketched here. It's better for the account presented here to be schematic, rather than tethered to some highly specific, contentious view in epistemology.

I suspect, however, that passing the buck entirely would be unsatisfying: we do, and should, want solutions to the problems, not just reasons to defer

\footnotetext{
${ }^{15}$ This is in part because more has been packed in to how "reasons" are understood in epistemology than in metaethics. For one, a "mentalist" ontology is often thought to be essential to the notion of "epistemic reasons": see Littlejohn 2012. For another, "epistemic reasons" are sometimes identified with motivating rather than normative reasons: for example, Turri sets aside the "reasons that there are to believe Q" and focuses on "epistemic reasons," which "differ importantly" because "reasons that there are to believe Q need not be had" and "are always good reasons to believe Q" $(2009,492)$.

${ }^{16}$ As Feldman $(1988,410)$ observes, whether such commitments are embraced partly depends on how they are formulated. He offers several explanations for this.

${ }^{17}$ See the many references in Feldman (1988), who is critical of this analogy.

${ }^{18}$ See McPherson and Plunkett 2015, 114 on 'Truth-Directedness,' and the many references to epistemologists who endorse such a principle referenced therein.
} 
to others in the hope that they can find them. Given that, I will sketch a way for objectivists who've followed me this far to proceed further and explain the unity of favoring, with the important caveat that there are plenty of other options that an objectivist could take at this juncture depending on her broader commitments about epistemology.

For the sake of brevity, then, let me present a highly schematic view about first how to unify objective and subjective reasons (or norms or . . .) for belief. The basic idea involves a distinction in scope. The objective reasons to believe $p$ include the fact that $p$. The objective reasons to disbelieve $q$ include the fact that not- $q$. The scope here is narrow: particular belief states. But we can also consider how objective reasons favor something more general than particular belief states, such as belief-forming methods.

The crucial point is that our evaluations of particular beliefs and beliefforming methods can come apart. It may be that a belief in $p$ is true (and hence favored by objective reasons), but a belief in not- $p$ is what will result from using the best belief-forming method (roughly, the one that's most reliable, or most favored by objective reasons). This gives us a need to introduce subjective reasons for belief. But those subjective reasons aren't an utterly distinct entity; they're ultimately explained in terms of the objective reasons for believing propositions and how those reasons favor belief-forming methods rather than particular beliefs. To put things differently given the lesson that we must focus on the relations and not the relata, the distinction between the objective and subjective reasons relations is not a distinction between favoring and something else, but a distinction between favoring believing propositions directly and indirectly.

This is a promising solution to the question of what unifies objective and subjective favoring. Notice that it requires us to reside in the area of logical space that has been neglected by objectivists. That is, we do not explain the subjective reasons for $A$ to form a particular belief in $p$ in terms of the objective reasons for $A$ to believe $p$. Rather, we explain the subjective reasons to believe $p$ in terms of the objective reasons to use a particular method from which believing in $p$ will be a result. The pattern of explanation here has to be indirect.

There's a lot here that needs to be filled in. As I noted, going with beliefforming methods is just one option among many. One could also appeal to another object of evaluation here; there are plenty of options that are more general than particular beliefs, such as sets of beliefs. ${ }^{19}$ There's also the question of exactly how we evaluate this more general object of evaluation.

\footnotetext{
${ }^{19}$ An anonymous referee objects to that option on the following ground: "a reason to believe a set of propositions would seem to be a reason to believe each proposition in that set-at least, it is far from clear how one could have a reason to have beliefs 1- $n$ without having a reason to form each such belief. This would imply (implausibly) that there is a subjective reason to believe $\mathrm{P}$ when there is an objective reason to believe P." This is an interesting objection that I don't have time to explore here, but I think it's worth considering in relation to the discussion of sets of credences in the next section.
} 
The assessment can be teleological: Does this belief-forming mechanism maximize reliability? But I do not think it needs to be teleological for the picture I'm developing here to work..$^{20}$ And of course, there's the familiar question of how to specify the "right kind of reasons" that count in favor of these belief-forming methods. As I've indicated, my view is that the right kind of reasons here are objective reasons for beliefs, but if one is open to a kind of pragmatism about the relevant facts that favor using belief-forming methods (or adopting particular beliefs), that will change the picture dramatically. ${ }^{21}$ This should be no surprise-part of the point of the schema is that it can be coupled with different commitments.

\section{Conclusion and Coda}

I would be extremely surprised if there were not deep and difficult questions regarding how to fill in the details of the schematic version of objectivism that I sketched above. And I would be remiss if I pretended that I could answer all of them. My hope, however, is that sticking to the big picture lets us see the structural virtues of this account. The account departs quite significantly from forms of objectivism that seek to explain each one of $A$ 's subjective reasons to $\varphi$ in terms of $A$ 's objective reasons to $\varphi$. And in doing so, it has a better hope of unifying the objective and subjective reasons relations for actions and attitudes with correctness conditions. This is, I hope, enough to motivate treating objectivist accounts with this indirect pattern of explanation as serious contenders in this area, and considering the various ways that the schema above can be filled in.

To reach the more immodest conclusion that some version of this schematic view should be accepted, rather than merely taken seriously, would require much more. It'd require not just filling in the schema, but fully assessing that more detailed view in comparison to rival objectivist views. I lack the space for any such endeavor here, but I can say a few things to assuage distinctive concerns that you might have about the view, and suggest some further virtues that it has in comparison to its rivals.

You might think that the view just sketched incurs some distinctive commitments that are implausible. For instance, the commitment to an indirect explanation of subjective reasons suggests an interesting difference between objective and subjective reasons, which does not seem to match our discourse. Atomic propositions get to be objective reasons (the fact that $p$ is an objective reason to believe $p$ ). But how do atomic propositions

\footnotetext{
${ }^{20}$ Berker $(2013,339)$ discusses what he calls the "article of faith in much recent epistemological theorizing" that "epistemic norms are guided by . . . the twin goals of acquiring true beliefs and avoiding false ones. ... [And] all other normative notions in epistemology are ultimately explicable in terms of how well the objects of assessment conduce toward, promote, or otherwise subserve these epistemic goals." But I take it that Berker only criticizes a teleological formulation of this view $(2013,343)$.

${ }^{21}$ Thanks to an anonymous referee for pushing the "wrong kind of reasons" problem.
} 
get to be subjective reasons? On the view I've proposed, the explanation for why there is a subjective reason for $A$ to believe $p$ goes ineliminably via a set or method. So how can objectivists like me explain our common ways of talking about ' $a$ ' or 'the' subjective reason to $\varphi$ ?22

This is a prima facie problem, but it has a solution. Fogal (2016) defends a view on which talk of ' $a$ ' or ' $t$ ' $e$ ' reason for $A$ to $\varphi$ is often best understood as a way of picking out a representative member of the set of factors that explain the relevant normative status. This mimics views on which talk of ' $a$ ' or ' $t$ ' $e$ ' cause is best understood as a way of picking out a representative member of the set of factors that explain the relevant causal relationships: see Swanson 2010. If this is plausible, we can easily explain talk of ' $a$ ' or 'the' subjective reason to $\varphi$ in terms of representative members of sets.

More generally, I think the variety of options that are available once we take the route of offering an indirect explanation of subjective reasons makes it hard to show that this fresh start can only lead to dead ends. In contrast, the resources that become available on the indirect route look an awful lot better than the resources we get from occupying the narrow terrain that is currently crowded with various forms of objectivism. I have framed this paper in terms of explaining the unity of favoring, but let me end with an illustration of another benefit of this objectivist approach.

Consider $\mathrm{C}$ once more. It is designed to explain why you have subjective reasons to act in cases of acting on false full beliefs. In this respect, it is like many prominent accounts of reasons, which, as Wedgwood (2015, 134) noted, provide "a picture that in a systematic way overestimates the centrality of outright belief." This leaves a glaring problem: What about when we have subjective reasons where we're acting on uncertainty about the truth, rather than confidence in falsehoods? What about partial beliefs?

Views like $\mathrm{C}$ face a serious problem here. Take a case where Carla knows that if she does not take a pill, she will die painlessly. But she does not know what the pill will do. She justifiably assigns a .5 credence to two possibilities: it will cure her completely, or it will kill her painfully. In fact, it will kill her painfully. This is a hard case for C-and, as I argue in Wodak 2017, for most of its current rivals—partly because there's no good candidate for a proposition that Carla believes such that if it were true it would be an objective reason for Carla to take the pill.

Schroeder (2018) recently responded that we can solve this problem by taking on a host of commitments, including endorsing a form of expressivism about epistemic modals, and denying the orthodoxy that all propositions are intrinsically representational. On Schroeder's approach, one can say that Carla believes that the pill is .5 likely to cure her (this belief just is her .5 credence), and from certain perspectives one can say that this belief is true and is an objective reason for her to take the pill. From other perspectives, Carla's belief is false and so it is not an objective reason to take the pill. As a result, objective reasons turn out to be "perspectivedependent," and so "objective reasons and objective 'ought' judgments are

\footnotetext{
${ }^{22}$ I thank Julia Staffel for pushing a version of this concern.
} 
along a certain dimension less objective than has been nearly universally assumed throughout moral philosophy" $(2018,314)$.

There's much to say about the merits of Schroeder's picture. But all I want to say here is that the view I have defended generalizes to credences and subjective probabilities without incurring such heterodox commitments. For instance, on one common view, ${ }^{23}$ we can assess particular partial beliefs by how "accurate" or "close to the truth" they are: if $p$ is true, a credence of .9 in $p$ is more accurate or closer to the truth than a credence of .8 in $p$. We can also assess credence functions for their total accuracy. ${ }^{24}$ As before, what's crucial is that the two evaluations can come apart. A partial belief (.99 in $p$ ) can be more accurate, but incompatible with the result of the most accurate credence function. This gives us a need to posit subjective reasons for the partial beliefs (e.g., .1 in $p$ ) that result from the most accurate credence function, just as we needed to posit subjective reasons for full beliefs (e.g., believing $p$ ) that result from the most reliable belief-forming methods. (One could also do this in terms of sets of credences that meet certain constraints, if one is allergic to talk of credence functions. ${ }^{25}$ ) We explain those subjective reasons for partial beliefs indirectly in terms of objective reasons for beliefs, as before.

Once we have this part of the story, we can start to see how Carla can have a subjective reason to form a credence of .5 in the proposition $<$ the pill will cure me completely>, even though that proposition is false. The schematic view on its own doesn't tell us exactly why that gives her a subjective reason to take the pill; we need to supply a bit more detail, but not that much. One option here is to again take reasons for $A$ to $\varphi$ to decompose into reasons for $A$ to desire to $\psi$ and reasons for $A$ to believe that $\varphi$ ing is a means to $\psi$ ing. If we take this route, we can also explain reasons for $A$ to $\varphi$ in terms of reasons for $A$ to prefer to $\psi$ and reasons for $A$ to adopt certain credences in the proposition $\langle\varphi$ ing is a means to $\psi$ ing $>$. Carla's credence, after all, concerns a proposition, $<$ the pill will cure me completely $>$, that is as plausible a candidate as any for identifying a means to an end that she has reason to desire and prefer (namely: living).

What this illustrates is that the objectivist view that I have sketched above opens up room for decision-theoretic explanations for why Carla has a subjective reason to take the pill. ${ }^{26}$ The view works for full and partial beliefs, without requiring expressivist machinery or heterodox commitments about propositions and the perspective-dependent nature of objective reasons. This, to my mind, is a comparative virtue. And while it may only seem like a virtue relative to Schroeder's specific account, it should be emphasized here that objectivist accounts of subjective reasons that can work for subjective probabilities are few and far between.

\footnotetext{
${ }^{23}$ For a recent application and general references, see Williams 2018, 131.

${ }^{24}$ For a detailed discussion of this, see Pettigrew 2016, especially 48-51.

${ }^{25}$ For this to work, we need constraints on sets of partial beliefs. For critical discussion of common views about how to derive such constraints, see Eriksson and Hájek 2007.

${ }^{26}$ In case this isn't clear, the account here is significantly inspired by Jackson (1991).
} 
I hope that this final point helps to advertise the attractive features of the objectivist guide to subjective reasons that I've sketched here. I recognize that it has been sketched at such a high level of abstraction that much work remains to be done. (Perhaps a better title would have been 'An Advertisement for a Sketch of an Outline of a Proto-Theory of Subjective Reasons,' with apologies to Stephen Yablo.) But sometimes a high level of abstraction is helpful for seeing the lay of the land. By going in for simple, direct explanations of subjective reasons, objectivists have painted themselves into a corner. It's helpful to see the vistas that open up when we provide indirect explanations of subjective reasons in terms of objective reasons for belief, prior to coloring in the details by using our favorite familiar views from epistemology and decision theory.

Daniel Wodak

Virginia Polytechnic Institute and State University E-mail: dwodak@vt.edu

References:

Alvarez, Maria. 2010. Kinds of Reasons. Oxford: Oxford University Press.

Berker, Selim. 2013. "Epistemic Teleology and the Separateness of Propositions." Philosophical Review 122 (3): 337-393. https://doi.org/10.1215/00318108-2087645.

Boghossian, Paul. 2003. "The Normativity of Content." Philosophical Issues 13 (1): 31-45. https://doi.org/10.1111/1533-6077.00003.

Broome, John. 2013. Rationality Through Reasoning. Oxford: Wiley.

Dorsey, Dale. 2012. "Objective Morality, Subjective Morality, and the Explanatory Question." Journal of Ethics and Social Philosophy 6 (3): 1-24. https://doi.org/10.26556/jesp.v6i3.65.

Eriksson, Lina and Alan Hájek. 2007. "What Are Degrees of Belief?” Studia Logica 86 (2): 185-215. https://doi.org/10.1007/s11225-007-9059-4.

Faraci, David. Forthcoming. "We Have No Reasons to Think There Are No Reasons for Affective Attitudes.” Mind. First Published Online 2018.

Feldman, Richard. 1988. "Subjective and Objective Justification in Ethics and Epistemology." The Monist 71 (3): 405-419. https://doi.org/10.5840/monist198871326.

Fogal, Daniel. 2016. "Reasons, Reason, and Context." In Weighing Reasons, edited by Errol Lord and Barry Maguire. Oxford: Oxford University Press.

Hedden, Brian. 2016. "Does MITE Make Right?: Decision-Making Under Normative Uncertainty." In Oxford Studies in Metaethics, edited by Russ Shafer-Landau, Vol. 11, 102-128. Oxford: Oxford University Press.

Hyman, John. 2015. Action, Knowledge, and Will. Oxford: Oxford University Press.

Jackson, Frank. 1991. "Decision-Theoretic Consequentialism and the Nearest and Dearest Objection." Ethics 101 (3): 461-482. https://doi.org/10.1086/293312.

Kiesewetter, Benjamin. 2012. "A Dilemma for Parfit's Conception of Normativity." Analysis 72 (3): 466-474. https://doi.org/10.1093/analys/ans065.

Littlejohn, Clayton. 2012. Justification and the Truth Connection. Cambridge: Cambridge University Press.

Maguire, Barry. 2018. “There Are No Reasons for Affective Attitudes.” Mind 127 (507): 779-805. https://doi.org/10.1093/mind/fzx011.

Acknowledgments Thanks to Jonathan Dancy, Amelia Hicks, Walker Page, Nick Laskowski, Jack Woods, participants at the Saint Louis Annual Conference on Reasons and Rationality, and the editors and anonymous referees for Res Philosophica. 
Markovits, Julia. 2010. “Acting for the Right Reasons.” Philosophical Review 119 (2): 201-242. https://doi.org/10.1215/00318108-2009-037.

McPherson, Tristram and David Plunkett. 2015. "Deliberative Indispensability and Epistemic Justification." In Oxford Studies in Metaethics, edited by Russ Shafer-Landau, Vol. 10, 104133. Oxford: Oxford University Press. https://doi.org/10.1093/acprof:oso/9780198738695. 003.0005 .

Parfit, Derek. 2011. On What Matters. Vol. 2. Oxford: Oxford University Press.

Pettigrew, Richard. 2016. Accuracy and the Laws of Credence. Oxford: Oxford University Press.

Scanlon, T. M. 1998. What We Owe to Each Other. Harvard University Press.

Schaffer, Jonathan. 2016. "Ground Rules: Lessons from Wilson.” In Scientific Composition and Metaphysical Ground, edited by Kenneth Aizawa and Carl Gillett, 143-170. London: Palgrave.

Schroeder, Mark. 2007. Slaves of the Passions. Oxford: Oxford University Press.

Schroeder, Mark. 2009. "Means-End Coherence, Stringency, and Subjective Reasons." Philosophical Studies 143 (2): 223-248. https://doi.org/10.1007/s11098-008-9200-x.

Schroeder, Mark. 2015. "Knowledge Is Belief for Sufficient (Objective and Subjective) Reason." In Oxford Studies in Epistemology, edited by Tamar Szabó Gendler and John Hawthorne, Vol. 5, 226-252. Oxford University Press.

Schroeder, Mark. 2018. "Getting Perspective on Objective Reasons." Ethics 128 (2): 289-319. https://doi.org/10.1086/694270.

Schroeter, Laura and Francois Schroeter. 2009. "Reasons as Right-Makers." Philosophical Explorations 12: 279-296. https://doi.org/10.1080/13869790903067691.

Sepielli, Andrew. 2012. "Subjective Normativity and Action Guidance." In Oxford Studies in Normative Ethics, edited by Mark Timmons, Vol. 2. Oxford: Oxford University Press.

Sepielli, Andrew. 2018. "Subjective and Objective Reasons." In Oxford Handbook of Reasons and Normativity, edited by Daniel Star, 784-799. Oxford: Oxford University Press.

Stich, Stephen. 1990. The Fragmentation of Reason. Cambridge, MA: MIT Press.

Swanson, Eric. 2010. "Lessons from the Context Sensitivity of Causal Talk." The Journal of Philosophy 107 (5): 221-242. https://doi.org/10.5840/jphil2010107517.

Sylvan, Kurt. 2015. "What Apparent Reasons Appear to Be.” Philosophical Studies 172 (3): 587-606. https://doi.org/10.1007/s11098-014-0320-1.

Sylvan, Kurt and Ernest Sosa. 2018. "The Place of Reasons in Epistemology." In Oxford Handbook of Reasons and Normativity, edited by Daniel Star, 555-574. Oxford: Oxford University Press.

Thomson, Judith Jarvis. 2008. Normativity. Peru, IL: Open Court.

Turri, John. 2009. “The Ontology of Epistemic Reasons.” Nô̂s 43 (3): 490-512. https: //doi.org/10.1111/j.1468-0068.2009.00715.x.

Vogelstein, Eric. 2012. “Subjective Reasons." Ethical Theory and Moral Practice 15 (2): 239-257. https://doi.org/10.1007/s10677-011-9286-7.

Way, Jonathan. 2009. "Two Accounts of the Normativity of Rationality." Journal of Ethics and Social Philosophy 4 (1): 1-9. https://doi.org/10.26556/jesp.v4i1.130.

Wedgwood, Ralph. 2015. “The Pitfalls of 'Reasons'.” Philosophical Issues 25 (1): 123-143. https://doi.org/10.1111/phis.12054.

Whiting, Daniel. 2014. "Keep Things in Perspective: Reasons, Rationality and the A Priori." Journal of Ethics and Social Philosophy 8 (1): 1-22. https://doi.org/10.26556/jesp.v8i1.77.

Whiting, Daniel. 2017. "Right in Some Respects: Reasons as Evidence." Philosophical Studies 175 (9): 2191-2208. https://doi.org/10.1007/s11098-017-0954-х.

Williams, Robbie. 2018. "Rational Illogicality." Australasian Journal of Philosophy 96 (1): 127-141. https://doi.org/10.1080/00048402.2017.1323933.

Wodak, Daniel. 2017. "Can Objectivists Account for Subjective Reasons?” Journal of Ethics and Social Philosophy 12 (3): 259-279. https://doi.org/10.26556/jesp.v12i3.246.

Wodak, Daniel. Unpublished manuscript a. "Redundant Reasons."

Wodak, Daniel. Unpublished manuscript $b$. "Who's On First." 